\title{
Development of a new method for identifying species affiliation based on forensic hair examination
}

\author{
YURIY A. BALJI, JANAT SH. ADILBEKOV, JAN WIŚNIEWSKI*, \\ ZBIGNIEW BEŁKOT**, KRZYSZTOF ANUSZ*
}

\begin{abstract}
Department of Veterinary Sanitation, Faculty of Veterinary Medicine and Technology of Animal Husbandry, S. Seifullin Kazakh Agro Technical University, Zhenis Avenue 62, 010011 Astana, Republic of Kazakhstan *Department of Food Hygiene and Public Health Protection, Faculty of Veterinary Medicine, Warsaw University of Life Sciences - SGGW, Nowoursynowska 159, 02-776 Warsaw, Poland **Department of Food Hygiene of Animal Origin, Faculty of Veterinary Medicine, University of Life Sciences in Lublin, Akademicka 12, 20-950 Lublin, Poland
\end{abstract}

Balji Y. A., Adilbekov J. Sh., Wiśniewski J., Bełkot Z., Anusz K.

\section{Development of a new method for identifying species affiliation based on forensic hair examination}

\section{Summary}

The aim of the research was to develop a method for determining the species affinity of animal hair by determining its melting temperature. The research material was selected from hair samples of livestock and wild animals. We investigated 170 hairs of 16 animal species and humans. The hair melting point was determined by an automated system for melting temperature determination Opti Melt (MPA100). In the present study, we suggest that species affiliation can be effectively determined by examining physical properties of hair, in particular by determining its melting temperature. The hair melting temperatures for different animal species are in different ranges, but the initial melting points for hair of certain animal species are similar. For example, the initial melting point for cat, sheep, hare, rabbit, and rat hair ranged from 100 to $111^{\circ} \mathrm{C}$, and the hair of the wolf, bear, and fox began to melt at 139.2 to $141.2^{\circ} \mathrm{C}$. The results of this research make it possible to determine the species affinity of animals according to their hair melting temperature, which had not been done before. The proposed method yields rapid results and can be used as an auxiliary method in ambiguous cases in which data obtained by microscopic examination are insufficient. It will greatly facilitate the work of forensic specialists, enriching the arsenal of available methods.

Keywords: forensic examination, animal hair, human hair, species affiliation

Veterinary forensic science is one of multiple applications of veterinary medicine. Currently, one of its most urgent problems is the identification of animal species based on their carcass, internal organs, bones and, in some cases, hair, especially the structure of hair. This need is particularly acute considering the increasing incidence of animal theft, illegal animal slaughter, poaching, theft of animal fur and skins, etc. All the aforementioned types of evidence may be found at the crime scene, as well as on crime tools, weapons, vehicles, clothing, etc. $(19,28)$.

As reported in the literature, animal hair serves as valuable biological evidence in such cases as the ones mentioned above. Thus, from the perspective of veterinary forensic scientists, research on animal hair is a matter of considerable importance $(17,18,26)$.

The research methods applied by contemporary forensic biology in examining animal hair have been developed thanks to the achievements of biological sciences and specific experiments. These methods are based on general biological assumptions, forensic identification techniques and forensic diagnostics (4, $23,27)$.

The most recent tests for determining animal species are performed on the molecular level and consist in determining keratin specificity in animal species. However, in most cases, researchers use morphological analyses which identify specific anatomical structures of animal hair, especially the cortical fuse and medulla. Some methods combine microscopic examination with digital processing, in which the hair colour is identified by dedicated software (8). Other methods involve, among others, the analysis of the cross-section of animal hair with laser scanning confocal microscopes (14). The ramifications of the elimination of biological factors influencing the condition of animal hair, 
including its condition upon an animal's death, have also been studied, enabling scientists to draw certain conclusions (25). Bertranda et al. (6) described the historical significance of hair.

The identification of an animal's sex based on its hair is possible because of the difference in the set of chromosomes in males and females in terms of chromatic formations detected by cytological examinations. Ayat H. B. Rashaid et al. (22) studied the amino acid composition of keratin, which is a key component of hair. The statistical analysis of data for 64 subjects, including 33 men and 31 women aged 1 to 77 years, showed that it is possible to determine the sex, age and region of origin based on the amino acid composition of hair. Laatsch et al. (16) identified ethnicity by studying differences in human hair proteins.

Despite the above-mentioned achievements in the study of animal hair, forensic scientists and biologists are still facing difficulties in applying appropriate expertise because of the incompleteness of data on the macroscopic hair structure of many species and the unavailability of illustrative materials that could be used to differentiate between and identify hair of different species. Pilli et al. (21) studied the significance and complexity of animal hair by analysing its morphological characteristics and DNA. Birngrubera et al. (7) reported problems in identifying species affiliation by DNA analysis when examining hair originating from an unknown number of species.

There are a number of studies dedicated to detection of foreign matter in hair, including drugs $(1,10$, $24)$, medicinal products $(12,15)$, alcohol $(2,5,10)$, toxic substances (13), explosives (20) and others (3, 11). However, there is almost no data on the physical characteristics of hair, especially its melting point.

By analysing hair, forensic specialists may achieve the following goals: (1) determine whether presented objects are hair, (2) identify the species affiliation of a given hair sample (i.e. determine whether a given hair sample is characteristic of a specific human or animal species), (3) determine whether a hair sample constituting forensic evidence has been removed or has fallen out, (4) determine any damage or changes to a given hair sample (e.g. moulting), (5) identify to which animal species a given hair sample belongs, (6) determine whether a given hair sample originates from a specific animal species, (7) identify any foreign matter (e.g. toxic substances) present in a given hair sample. The above is not a complete list of information that can be obtained by analysing hair samples (26).

Microscopy research and techniques are not always successful in identifying species affiliation. Therefore, to address this key issue, it is necessary to expand the scope of animal hair properties examined and to develop research methods that are less expensive than DNA analysis. The aim of this study was to develop a method of identifying species affiliation based on the melting point of animal hair.

\section{Material and methods}

The research material was collected and selected from hair samples of livestock and wild animals. It consisted of 170 hair samples from 16 species, including humans.

The melting points of the hair samples were measured and calculated with the use of OptiMelt MPA100 (by Stanford Research Systems) an automated system that provides fast and accurate measurements of melting points and melting ranges of chemical substances. It is compatible with Pharmacopeia and GLP regulations. The device measures melting points and melting ranges of samples of various materials with a diameter of up to $2 \mathrm{~mm}$. The hairs were cut into sections of 2-3 mm. Three sections of each hair sample were placed in different melting tubes and three repetitions were performed. The results were calculated on the basis of images of hair samples taken in real time with a built-in camera. The melting points or melting ranges are displayed on the front panel and automatically stored by the device. The following parameters were set in the system: the initial melting point $\left(70^{\circ} \mathrm{C}\right)$, the final melting point $\left(250^{\circ} \mathrm{C}\right)$ and the speed of measuring melting points $\left(5^{\circ} \mathrm{C} / \mathrm{min}\right)$. Before measurements, the device was calibrated using standard samples included in the kit (Vanillin, Phenacetin, Caffeine), in accordance with the current protocols of the European Pharmacopoeia.

\section{Results and discussion}

The research results presented here are a brief summary of the method proposed for identifying species affinity on the basis of animal hair. In the future, however, more detailed studies may be required to determine melting points for different types of animal hair of each animal species (i.e. guard hairs, awn hairs, under hairs, sinus hairs, intermediate coat), taking into account the age of an animal. At the present stage of research, we studied guard hairs of middle-aged animals of different species.

Due to the fact that hair burns rather than melts, potassium hydroxide ( $\mathrm{KOH}$ pure) was placed in the melting tube together with the hair (2-3 mm sections). It was an important factor for the effectiveness of this method of determining hair melting points. The Melt View software made it possible to observe the hair sample on the screen of the device and record the entire melting process. The results obtained in these analyses are presented in Table 1.

The minimum and maximum melting points shown for each temperature range indicate the average initial melting point and the average final melting point, respectively. Table 1 shows that, although melting ranges for different animal species vary, the initial melting points for certain animal species are similar. The species were therefore grouped according to the calculated initial melting points. Differences in final melting points for some animal species made it possible to identify species affinity within each group. Nevertheless, hair samples from some other animal species, namely the sheep, hare, deer and lynx, showed similar final melting points. 
Tab. 1. Melting points and melting ranges of animal hair of different animal species

\begin{tabular}{|c|c|c|}
\hline No & Animal species & Melting range \\
\hline \multicolumn{3}{|c|}{ Group $1-100.0-188.7^{\circ} \mathrm{C}$} \\
\hline 1 & Cat & $100.0 \pm 0.10-181.7 \pm 0.64$ \\
\hline 2 & Sheep & $102.3 \pm 0.38-184.6 \pm 0.52$ \\
\hline 3 & Hare & $104.2 \pm 0.27-183.7 \pm 0.98$ \\
\hline 4 & Rabbit & $105.5 \pm 0.42-178.7 \pm 0.34$ \\
\hline 5 & Rat & $111.9 \pm 0.53-188.7 \pm 0.89$ \\
\hline \multicolumn{3}{|c|}{ Group $2-116.1-179.4^{\circ} \mathrm{C}$} \\
\hline 6 & Dog & $116.1 \pm 0.32-179.4 \pm 0.41$ \\
\hline \multicolumn{3}{|c|}{ Group $3-120.9-197.3^{\circ} \mathrm{C}$} \\
\hline 7 & Marten & $120.9 \pm 0.40-177.2 \pm 0.46$ \\
\hline 8 & Cow & $123.9 \pm 0.52-189.4 \pm 1.04$ \\
\hline 9 & Horse & $125.1 \pm 0.27-197.3 \pm 0.54$ \\
\hline \multicolumn{3}{|c|}{ Group $4-130.7-190.9^{\circ} \mathrm{C}$} \\
\hline 10 & Pig & $130.7 \pm 0.33-190.9 \pm 1.07$ \\
\hline \multicolumn{3}{|c|}{ Group $5-138.8-170.3^{\circ} \mathrm{C}$} \\
\hline 11 & Ferret & $138.8 \pm 0.43-174.7 \pm 0.69$ \\
\hline 12 & Wolf & $139.2 \pm 0.46-176.9 \pm 0.79$ \\
\hline 13 & Deer & $140.1 \pm 0.41-173.9 \pm 0.77$ \\
\hline 14 & Bear & $140.9 \pm 0.62-179.2 \pm 0.92$ \\
\hline 15 & Fox & $141.2 \pm 0.23-166.7 \pm 0.49$ \\
\hline 16 & Lynx & $141.5 \pm 0.54-173.5 \pm 1.00$ \\
\hline 17 & Human & $143.2 \pm 0.34-170.3 \pm 0.80$ \\
\hline
\end{tabular}

The results of this study suggest the possibility of identifying species affiliation by a new rapid method based on the melting temperature of animal hair. This method had never been used before. Due to the fact that hair burns rather than melts at very high temperatures, the measurement of the initial and final melting points of the hair samples required the use of alkaline substances that destroy the cortical cells of hair and denature collage, a hair protein. This new method may serves as an auxiliary method in ambiguous cases in which data obtained by microscopic examination is insufficient. It would greatly facilitate the work of forensic scientists, enriching the arsenal of the available methods.

An application for the patent for the newly developed method of identifying species affiliation based on hair examination has been filed at the National Institute of Intellectual Property of the Ministry of Justice of the Republic of Kazakhstan.

\section{References}

1. Ago M., Ago K., Ogata M.: Determination of methamphetamine in sudden death of a traffic accident inpatient by blood and hair analyses. Legal Medicine 2009, 11, Supp. 1, 568-569.

2. Albermann M. E., Musshoff F., Madea B.: A fully validated high-performance liquid chromatography-tandem mass spectrometry method for the determination of ethyl glucuronide in hair for the proof of strict alcohol abstinence. Anal. Bioanal. Chem. 2010, 396, 2441-2447.

3. Balíková M.: Hair analysis for drugs of abuse. Plausibility of interpretation. Biomed. Pap. Med. Fac. Univ. Palacky Olomouc Czech Repub. 2005, 149, 199-207.
4. Bashkireva E. A., Belsky K. V.: Assessment of animal hair research in forensic medical practice. Topical problems of forensic medicine and medical law. Materials of scientific-practical conference with international participation, dedicated to the memory of Professor V.O. Plaksin. Moscow 2011.

5. Baumgartner M. R.: Nachweis des Konsums von psychotropen Substanzen und Alkohol mittels Haaranalyse. Therap. Umschau 2011, 68, 269-273.

6. Bertranda L., Vichia A., Doucetc J., Walterd P., Blanchard P.: The fate of archaeological keratin fibres in a temperate burial context: microtaphonomy study of hairs from Marie de Bretagne ( $15^{\text {th }} \mathrm{c}$., Orléans, France). J. Archaeolog. Sci. 2014, 42, 487-499.

7. Birngrubera Ch., Ramsthalerb F., Verhoff M. A.: The color(s) of human hairForensic hair analysis with Spectra Cube ${ }^{\circledR}$. Forensic Sci. Internat. 2009, 185, 19-23.

8. Brooks E., Comber B., Naught I. Mc, Robertson J.: Digital imaging and image analysis applied to numerical applications in forensic hair examination. Science Justice 2011, 51, 28-37.

9. Cordero R., Lee S., Paterson S.: Distribution of Concentrations of Cocaine and its Metabolites in Hair Collected Postmortem from Cases with Diverse Causes/ Circumstances of Death. J. Anal. Toxicol. 2010, 34, 543-548.

10. Favretto D., Snenghi R., Terranova C., Montisci M., Ferrara S. D.: Assessing Fitness to Drive in Alcohol Abusing Drivers: Forensic Ethyl Glucuronide in Hair Performs Better than Clinical Biomarkers. Traffic Inj. Prev. 2014, 15, 251-254.

11. Kintz P.: Bioanalytical procedures for detection of chemical agents in hair in the case of drug-facilitated crimes. Analyt. Bioanal. Chem. 2007, 388, 1467-1474.

12. Kintz P., Evansb J., Villaina M., Salquebrea G., Cirimele V.: Hair analysis for diphenhydramine after surreptitious administration to a child. Forensic Sci. Internat. 2007, 173, 171-174

13. Kintz P., Ginet M., Marques N., Cirimele V: Arsenic speciation of two specimens of Napoleon's hair. Forensic Sci. Internat. 2007, 170, 204-206.

14. Kirkbride P. K., Tridico $S$. R.: The application of laser scanning confocal microscopy to the examination of hairs and textile fibers: An initial investigation. J. Forensic Sci. Internat. 2010, 195, 28-35.

15. Krumbiegel F., Hastedt M., Eichberg S., Correns N., Gapert R., Hartwig S. Herre S., Tsokos M.: Hair analysis in the detection of long-term use of nonsteroidal anti-inflammatory drugs and its relation to gastrointestinal haemorrhage: an examination of 268 hair and blood samples from autopsy cases. Forensic Sci. Med. Pathol. 2014, 10, 18-28.

16. Laatsch Ch. N., Durbin-Johnson B. P., Rocke D. M., Mukwana S., Newland A. B., Flagler M. J., Davis M. G., Eigenheer R. A., Phinney B. S., Rice R. H. Human hair shaft proteomic profiling: individual differences, site specificity and cuticle analysis. Peer J. 2014, 2, 506.

17. Lykhina L. Y.: Determination of animal species on the hair structure. Abstract of doctoral thesis in Veterinary Sciences. Bishkek 2011, 27.

18. Maikanov B. S., Balji Yu.: Forensic Veterinary Sanitary Examination. Textbook. Astana 2013, 272.

19. Malovasty K. S.: Determination of Meat Species Affinity. Textbook. Bryansk $2013,65$.

20. Oxley J. C., Smith J. L., Kirschenbaum L. J., Marimiganti S., Efremenko I., Zach R., Zeiri Y: Accumulation of Explosives in Hair-Part 3: Binding Site Study. J. Forensic Sci. 2012, 57, 623-635.

21. Pilli E., Casamassima R., Vai S., Virgili A., Barni F., D’Errico G., Berti A., Lago G., Caramelli D.: Pet fur or fake fur? A forensic approach. Investig. Genetics 2014, 5:7

22. Rashaid A. H. B., Jackson G. P., Harrington P. B.: Amino acid composition of human scalp hair as a biometric classifier and investigative lead. Anal. Methods 2015, 7, 1707-1718.

23. Sato I., Nakaki S., Murata K., Takeshita H., Mukai T.: Forensic hair analysis to identify animal species on a case of pet animal abuse. Internat. J. Legal Med. 2010, 124, 249-256.

24. Stybe Johansen S., Dahl-Sorensen R.: A drug rape case involving triazolam detected in hair and urine. Internat. J. Legal Med. 2012, 126, 637-643.

25. Tridico S. R., Houck M. M., Kirkbride K. P., Smith M. E., Yates B. C. Morphological identification of animal hairs: Myths and misconceptions, possibilities and pitfalls. J. Forensic Sci. Internat. 2014, 238, 101-107.

26. Tridico $S$. R., Koch $S$, Michaud A., Thomson G., Kirkbride P. K., Bunce M Interpreting biological degradative processes acting on mammalian hair in the living and the dead: which ones are taphonomic? Proc. Royal Soc. B - Biol. Sci. 2014, 281, 1796 .

27. Vaughnal M. R., Brooksa E., Oorschota R. A. H. van, Baindur-Hudsona S. A Comparison of Macroscopic and Microscopic Hair Color Measurements and a Quantification of the Relationship between Hair Color and Thickness. Microscopy Microanalysis 2009, 15, 189-193.

28. Zenke P., Egyed B., Pádár Z., Kovács $G$.: Increasing relevance of non-human genetics in Hungarian forensic practice. Forensic Science International: Genetics Supp. Ser. 2015, 5, 250-252.

Corresponding author: Yuriy A. Balji, Ass. Prof., Department of Veterinary Sanitation, Faculty of Veterinary Medicine and Technology of Anima Husbandry, S. Seifullin Kazakh Agro Technical University, Zhenis Avenue 62 010011 Astana, Republic of Kazakhstan; e-mail: Balji-Y@mail.ru 